\title{
Educational Status of Mothers and their Pre-natal and Post-natal Care of Infants in Bangladesh
}

\author{
Sanjoy Kumar Chanda ${ }^{1}$, Shaharior Rahman Razu ${ }^{2}$, Shahana Shrin ${ }^{3}$

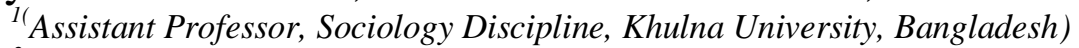 \\ ${ }_{2}^{2}$ (Part-time Lecturer, Sociology Discipline, Khulna University, Bangladesh) \\ ${ }_{3}^{3}$ (Student, Child Development and Family Relation Department, KCCWC, Bangladesh)
}

\begin{abstract}
Educational status of the married women and their conception about pre-natal and post natal care of infants in rural and urban Bangladesh differ from each other to a significant scale. This study was conduced on married women aged from 16 years to 35 years who had at least one child bearing the age below one year. The study area of this research was Khulna city ward no. 24 (considered as the urban study area) and Sonka village of Kaliganj upazila in Satkhira (considered as the rural study area) in Bangladesh. The objective of the study was to understand the educational status of mother and their concept about pre-natal and post-natal care in rural and urban Bangladesh. The study is an explanatory research based where survey research design was used mainly. A total of 100 respondents were selected equally from both urban and rural area following purposive sampling method. It was found from the study that 56 percent of the rural mothers and 36 percent of the urban mothers had education up to primary level (equal to $5^{\text {th }}$ Grade). Findings also reveal that 84 percent of the rural mothers and 48 percent of the urban mothers had rest hours below one to a day. The findings suggest that education had a significant influence over the conception of mothers regarding pre-natal and postnatal care of the infants with a significant variance in the rural and urban areas.
\end{abstract}

Key Words: Education, Pre-natal, Post-natal, Infants, Mothers, Health Care.

\section{Introduction}

The Educational status of mother plays an important role in determining the nature of pre-natal and post-natal infant care both in urban and rural areas. It is an issue of greater significance and to address the poor state of maternal, neonatal and child health $(\mathrm{MNCH})$ the government of Bangladesh has undertaken several initiatives since independence. ${ }^{[1]}$ Bangladesh has achieved some achievements in maternal and child health $(\mathrm{MCH})$ in the past three decades, with a greater contribution from public health and education interventions and investments. Initiatives include immunization, nutrition supplementation; family planning, the national oral rehydration solution (ORS) programmed stipend and other support for female education, and increased public expenditure on health (from $0.7 \%$ of GDP in 1990 to $1.5 \%$ in 1999-2001) and education (from 1.5\% of GDP in 1990 to $2.3 \%$ in 1999-2001). With all these good outcomes observed, some of the areas of reproductive health like infant mortality rates (IMR), neonatal mortality rates (NMR), maternal mortality rates (MMR) which are still very high. ${ }^{[2]}$

Previous studies showed that Educational program supported that nurses need to involve themselves through helpful method of the educational program to teach the mothers' knowledge about pneumonia and their behavior during caring their sick children. ${ }^{[3]}$ It is assumed that programs could effectively increase both knowledge and behavior of mothers of children under five with pneumonia. This is importantly applicable with the infant care aspect as well in this context. In order to improve the maternal, neonatal and child health, the government of Bangladesh has taken a sector wide approach (SWAP) along with poverty reduction strategies to give more attention towards maternal and child health, for attaining the MDGs. ${ }^{[4]}$

It was also found that some mothers believed that pneumonia was caused by evil influence and in this case the children were treated by spiritual healers; as a result allopathic treatment was delayed or avoided. ${ }^{[5]}$ Studies also suggest that educating mothers have found to be of significant importance in child care during disease and other health hazards. Giving more specific health education to the mothers regarding ARI (Acute Respiratory Infection) could minimize preventable deaths in children as assumed. ${ }^{[6]}$ It is observed that a positive impact of educational program for mothers regarding dietary advice in reducing respiratory symptoms in infants during the first year of life. ${ }^{[7]}$ Health education of mothers on childhood pneumonia and training of health staff on case management is of greater necessity as it can reduce severe ARI effectively. ${ }^{[8]}$ As observed, treatment of child and case management are highly important in ARI control program in Bangladesh. ${ }^{[9][10]}$

Importantly, education of the mothers becomes an issue of priority as a study revealed that only $59.9 \%$ of primary caretakers could identify the danger signs to seek help. At the same time, only $58.4 \%$ of parents sought help in presence of danger signs. ${ }^{[1]}$ Considering all these, the education of mother become very 
important again as they are the main care provider in the family. ${ }^{[12]}$ The scenario in both rural and urban areas are, therefore, an important issue of concern regarding educational status of mothers affecting the pre-natal and post natal care of infants in Bangladesh.

\section{Materials And Methods}

This explanatory study was conducted following the survey research design. The study area for the study was Ward no.24 in Khulna city as urban area and Sonka village of Kaliganj Upazila in Satkhira district as rural area. An interview schedule was constructed for data collection from 100 purposively selected respondents. The respondents were mothers of 16 to 35 years of age having at least one child aged below one year. Here, the pre-natal care referred to the regular medical and nursing care recommended for women during pregnancy while post natal care referred to the care of infants after their birth. The infants in this study are the babies who are yet to celebrate their first birthdays. Besides primary data, secondary data were collected and used for the purpose of the study from various sources in different stages of the study. After collecting the data, it were analyzed and interpreted by using descriptive and inferential statistical techniques with the help of SPSS software, MS-Excel and MS-Word applications.

\section{Findings and Discussion}

\subsection{Background factors Related to Mothers' Education and Pre-natal and Post-natal Infant Care}

Findings of the study reveal that the educational status of the mothers importantly affects the pre-natal and post-natal infant health care. Some of the background factors played pivotal role in determining the nature of pre-natal and post-natal care of the infants of the respondents. In this study, the majority of the respondents from the rural area were aged from 21 years to 25 years of age $(42.0 \%)$ whereas in urban areas the majority of the respondents were from 26 years to 30 years age category. The average age of the respondents in rural areas was 22.9 years and 26.5 years in urban areas. The standard deviation of the age of the rural women was 2.35 years while the standard deviation of the age of the urban women was 4.24 years. This finding clearly indicates that mothers in urban area are usually of much age than the rural area.

Rural respondents were maximum married $(88.0 \%)$ with 6.0 percent widowed and 6.0 percent divorced respectively. Also, in urban areas maximum women were married (94.0\%). in both rural area. The family type of the respondents in rural area was mixed with extended (54.0\%) and nuclear (46.0\%) family types. The urban families however were mostly nuclear $(94.0 \%)$ and the rest were extended type of family $(6.0 \%)$.

The educational status of the rural women was mostly confined to the primary level $(56.0 \%)$ and illiterate $(28.0 \%)$ whereas in urban areas the predominance of primary $(36.0 \%)$ secondary $(34.0 \%)$ higher secondary $(16.0 \%)$ and above higher secondary $(12.0 \%)$ were prevalent. Only 2.0 percent of the respondents were in illiterate category in educational status. Therefore, it is apparent that educational status was higher in urban areas rather than rural.

Table 1. Background Factors Related to Mothers' Education and Pre-natal and Post-natal Infant Care

\begin{tabular}{|c|c|c|}
\hline \multicolumn{2}{|c|}{ Age Categories (In Years) } & Percent \\
\hline \multirow{5}{*}{ Rural } & $16-20$ & 32.0 \\
\hline & $21-25$ & 42.0 \\
\hline & $26-30$ & 22.0 \\
\hline & $31-35$ & 4.0 \\
\hline & Total & 100.0 \\
\hline \multirow{5}{*}{ Urban } & $16-20$ & 12.0 \\
\hline & $21-25$ & 18.0 \\
\hline & $26-30$ & 56.0 \\
\hline & $31-35$ & 14.0 \\
\hline & Total & 100.0 \\
\hline \multicolumn{2}{|c|}{ Marital Status } & Percent \\
\hline \multirow{4}{*}{ Rural } & Married & 88.0 \\
\hline & Divorced & 6.0 \\
\hline & Widowed & 6.0 \\
\hline & Total & 100.0 \\
\hline Urban & Married & 94.0 \\
\hline
\end{tabular}




\begin{tabular}{|c|c|c|}
\hline & Divorced & 4.0 \\
\hline & Widowed & 2.0 \\
\hline & Total & 100.0 \\
\hline \multicolumn{2}{|c|}{ Family Type } & Percent \\
\hline \multirow{3}{*}{ Rural } & Nuclear & 46.0 \\
\hline & Extended & 54.0 \\
\hline & Total & 100.0 \\
\hline \multirow{3}{*}{ Urban } & Nuclear & 94.0 \\
\hline & Extended & 6.0 \\
\hline & Total & 100.0 \\
\hline \multicolumn{2}{|c|}{ Educational Status } & Percent \\
\hline \multirow{5}{*}{ Rural } & Illiterate & 28.0 \\
\hline & Primary & 56.0 \\
\hline & Secondary & 12.0 \\
\hline & Higher & 4.0 \\
\hline & Total & 100.0 \\
\hline \multirow{5}{*}{ Urban } & Illiterate & 2.0 \\
\hline & Primary & 36.0 \\
\hline & Secondary & 34.0 \\
\hline & Higher & 28.0 \\
\hline & Total & 100.0 \\
\hline \multicolumn{3}{|c|}{ Average Age in Rural Areas - 22.9 Years } \\
\hline \multicolumn{3}{|c|}{ Standard Deviation of Age in Rural Areas - 2.35 Years } \\
\hline \multicolumn{3}{|c|}{ Average Age in Urban Areas - 26.5 Years } \\
\hline \multicolumn{3}{|c|}{ Standard Deviation of Age in Urban Areas - 4.24 Years } \\
\hline
\end{tabular}

Source: Field Survey, 2012

\subsection{Education and Knowledge Factors regarding Pre-natal and Post-natal Health Care of the Infants}

Certain factors of education and knowledge affected the pre-natal and post-natal care of the children of the respondents as the findings show. The majority $(48.0 \%)$ of the respondents in rural areas gave up education between the age of 10 to 15 years and another 26.0 percent gave up education below the age of 10 years. On the other hand, in urban areas no respondent gave up education below the age of 10 and the majority of 68.0 percent of the respondents gave up education between the age of 15 and 20. The provider of first female health education in rural area was mothers $(66.0 \%)$ and elder sister $(18.0 \%)$ while in urban area majority of 84.0 percent respondents got first female health education from mothers and 12.0 percent got that from the sisters.

The age of first marriage in the rural area was predominantly from the age of 15 to 20 years $(46.0 \%)$ whereas in urban areas the age of first marriage found mostly from the age of 20 to 25 years. This clearly shows that the age of first marriage is higher in the urban areas rather than rural and that the early marriage is more prevalent in the rural areas. In rural area, the involvement in family planning was observed among 84.0 percent of the respondents and in urban area it was 96.0 percent. The use of contraceptives was found among 74.0 percent respondents in rural areas whereas 98 percent of the respondents were using the contraceptives. Also, in rural area 94 percent respondents got the first conception after marriage within one to three years. In urban area, 94 percent respondents got first conception after marriage within one to three years. From the findings it is clearly apparent that rural women conceived $\mathrm{n}$ a faster time than the urban ones.

Table 2. Education and Knowledge Factors regarding Pre-natal and Post-natal Health Care of the Child

\begin{tabular}{|c|c|c|}
\hline \multicolumn{2}{|c|}{ Age of Giving Up Education } & Percent \\
\hline \multirow{3}{*}{ Rural } & Below 10 & 26.0 \\
\cline { 2 - 3 } & $10-15$ & 48.0 \\
\cline { 2 - 3 } & $15-20$ & 22.0 \\
\cline { 2 - 3 } & $20-25$ & 4.0 \\
\hline
\end{tabular}




\begin{tabular}{|c|c|c|}
\hline & Total & 100.0 \\
\hline \multirow{5}{*}{ Urban } & Below 10 & 0.0 \\
\hline & $10-15$ & 12.0 \\
\hline & $15-20$ & 68.0 \\
\hline & $20-25$ & 20.0 \\
\hline & Total & 100.0 \\
\hline \multicolumn{2}{|c|}{ Provider of First Female Health Education } & Percent \\
\hline \multirow{5}{*}{ Rural } & Mother & 66.0 \\
\hline & Elder Sister & 18.0 \\
\hline & Grandmother & 4.0 \\
\hline & Others & 12.0 \\
\hline & Total & 100.0 \\
\hline \multirow{5}{*}{ Urban } & Mother & 84.0 \\
\hline & Elder Sister & 12.0 \\
\hline & Grandmother & 4.0 \\
\hline & Others & 0.0 \\
\hline & Total & 100.0 \\
\hline \multicolumn{2}{|c|}{ Age of First Marriage } & Percent \\
\hline \multirow{5}{*}{ Rural } & $11-15$ & 4.0 \\
\hline & $16-20$ & 46.0 \\
\hline & $21-25$ & 42.0 \\
\hline & $26-30$ & 8.0 \\
\hline & Total & 100.0 \\
\hline \multirow{5}{*}{ Urban } & $11-15$ & 2.0 \\
\hline & $16-20$ & 34.0 \\
\hline & $21-25$ & 38.0 \\
\hline & $26-30$ & 26.0 \\
\hline & Total & 100.0 \\
\hline \multicolumn{2}{|c|}{ Involvement in Family Planning } & Percent \\
\hline \multirow{3}{*}{ Rural } & Yes & 84.0 \\
\hline & No & 16.0 \\
\hline & Total & 100.0 \\
\hline \multirow{3}{*}{ Urban } & Yes & 96.0 \\
\hline & No & 4.0 \\
\hline & Total & 100.0 \\
\hline \multicolumn{2}{|c|}{ Use of Contraceptives } & Percent \\
\hline \multirow{3}{*}{ Rural } & Yes & 74.0 \\
\hline & No & 26.0 \\
\hline & Total & 100.0 \\
\hline \multirow{3}{*}{ Urban } & Yes & 98.0 \\
\hline & No & 2.0 \\
\hline & Total & 100.0 \\
\hline \multicolumn{2}{|c|}{$\begin{array}{c}\text { Time of First Conception after Marriage (In } \\
\text { Years) }\end{array}$} & \\
\hline \multirow{5}{*}{ Rural } & $1-3$ & 94.0 \\
\hline & $4-6$ & 6.0 \\
\hline & $7-9$ & 0.0 \\
\hline & 10 and above & 0.0 \\
\hline & Total & 100.0 \\
\hline \multirow{5}{*}{ Urban } & $1-3$ & 86.0 \\
\hline & $4-6$ & 10.0 \\
\hline & $7-9$ & 2.0 \\
\hline & 10 and above & 2.0 \\
\hline & Total & 100.0 \\
\hline
\end{tabular}

Source: Field Survey, 2012 


\subsection{Pre-natal and Post-natal Care of Mothers}

The pre-natal and post-natal care behavior is also an important aspect that is modified by the previous factors. The findings show that among rural respondents, rest hours during pregnancy per day belonged to below one to two hours for maximum 84.0 percent. While in urban area 48.0 percent of the respondents had below one to two hours of rest, 40.0 percent had three to four hours of rest majorly. This indicates that the rural women had usually less period of rest in pre-natal care stage in comparison to the urban respondents. Certain aspects of prenatal care of the children are related to various care taking processes. It was observed that in the rural area, 88.0 percent of the respondents too the T.T. injections while in urban area 98.0 percent of the respondents took that measure during the pre-natal stage. Also, in rural area 34.0 percent of the respondents were involved in heavy works during the pregnancy while in urban area the number was less (18.0\%) than the rural area.

The place of medical check-up during pregnancy varied significantly as the findings suggest from the study. In rural area, community hospitals and government hospitals were the majorly dominated place of checking up in the pregnancy period. In this time 60.0 percent respondents went to community hospitals and 32.0 percent of the rural respondents went to government hospitals. Whereas in urban area majorly 36.0 percent of the respondents went to the specialist doctors, 32.0 percent went to private hospitals, 16.0 percent went to government hospitals and 16.0 percent went to government hospitals. Due to various aspects of affordability and access matters this variation in rural and urban check-up places varied.

In post-natal care aspects the variation still is observed from the rural to urban respondents. In rural area, 96.0 percent of the respondents provided only mother milk in this period while in urban area 72.0 percent of the respondents provided the mother milk in this period along with 28.0 percent providing baby milks beside the mother milk. Also, 86.0 percent of the respondents in rural area provided the Vitamin-A' capsule to the child and in urban area 98.0 percent respondents provided the Vitamin-A' capsule to the child in this period. Among the rural respondents 92.0 percent mother could provide sufficient mother milk while $\mathrm{n}$ urban area 70.0 percent mother could provide sufficient mother milk in this period.

Table 3. Pre-natal Care of Mothers

\begin{tabular}{|c|c|c|}
\hline \multicolumn{2}{|c|}{ Rest Hours During Pregnancy per Day } & Percent \\
\hline \multirow{4}{*}{ Rural } & Below 1 to 2 & 84.0 \\
\hline & $3-4$ & 12.0 \\
\hline & 5-6 and above & 4.0 \\
\hline & Total & 100.0 \\
\hline \multirow{4}{*}{ Urban } & Below 1 to 2 & 48.0 \\
\hline & $3-4$ & 40.0 \\
\hline & $5-6$ and above & 12.0 \\
\hline & Total & 100.0 \\
\hline \multicolumn{2}{|c|}{ Taking of T.T. Injection } & Percent \\
\hline \multirow{3}{*}{ Rural } & Yes & 88.0 \\
\hline & No & 12.0 \\
\hline & Total & 100.0 \\
\hline \multirow{3}{*}{ Urban } & Yes & 98.0 \\
\hline & No & 2.0 \\
\hline & Total & 100.0 \\
\hline \multicolumn{2}{|c|}{ Involvement in Heavy Work during Pregnancy } & Percent \\
\hline \multirow{3}{*}{ Rural } & Yes & 34.0 \\
\hline & No & 66.0 \\
\hline & Total & 100.0 \\
\hline \multirow{3}{*}{ Urban } & Yes & 18.0 \\
\hline & No & 82.0 \\
\hline & Total & 100.0 \\
\hline \multicolumn{2}{|c|}{ Place of Medical Check Up during Pregnancy } & Percent \\
\hline \multirow{6}{*}{ Rural } & Government Hospitals & 32.0 \\
\hline & Private Hospitals & 4.0 \\
\hline & Community Hospitals & 60.0 \\
\hline & Specialists Doctors & 2.0 \\
\hline & Others & 2.0 \\
\hline & Total & 100.0 \\
\hline \multirow{3}{*}{ Urban } & Govt. Hospitals & 16.0 \\
\hline & Private Hospitals & 32.0 \\
\hline & Community Hospitals & 16.0 \\
\hline
\end{tabular}


Source: Field Survey, 2012

\begin{tabular}{|c|c|}
\hline Specialists Doctors & 36.0 \\
\hline Others & 0.0 \\
\hline Total & 100.0 \\
\hline
\end{tabular}

Table 4. Post-natal Care of Mothers

\begin{tabular}{|c|c|c|}
\hline \multicolumn{2}{|c|}{$\begin{array}{c}\text { Type of Milk Provided within Six } \\
\text { Months }\end{array}$} & Percent \\
\hline \multirow{3}{*}{ Rural } & Only Mother Milk & 96.0 \\
\hline & $\begin{array}{l}\text { Baby Milk Besides } \\
\text { Mother Milk }\end{array}$ & 4.0 \\
\hline & Total & 100.0 \\
\hline \multirow{3}{*}{ Urban } & Only Mother Milk & 72.0 \\
\hline & $\begin{array}{l}\text { Baby Milk Besides } \\
\text { Mother Milk }\end{array}$ & 28.0 \\
\hline & Total & 100.0 \\
\hline \multicolumn{2}{|c|}{$\begin{array}{c}\text { Providing 'Vitamin-A' Capsule to the } \\
\text { Child }\end{array}$} & Percent \\
\hline \multirow{3}{*}{ Rural } & Yes & 86.0 \\
\hline & No & 14.0 \\
\hline & Total & 100.0 \\
\hline \multirow{3}{*}{ Urban } & Yes & 98.0 \\
\hline & No & 2.0 \\
\hline & Total & 100.0 \\
\hline \multicolumn{2}{|c|}{$\begin{array}{l}\text { Providing Sufficient Mother Milk to the } \\
\text { Child }\end{array}$} & Percent \\
\hline \multirow{3}{*}{ Rural } & Yes & 92.0 \\
\hline & No & 8.0 \\
\hline & Total & 100.0 \\
\hline \multirow{3}{*}{ Urban } & Yes & 70.0 \\
\hline & No & 30.0 \\
\hline & Total & 100.0 \\
\hline
\end{tabular}

Source: Field Survey, 2012

3.4 Correlation between Educational Status of Mothers and Pre-natal and Post-natal Care of their Infants

The educational status can be correlated to different variables related to the pre-natal and post-natal care of infants by their mothers. Many aspects like age of first marriage, place of health check up, use of contraceptives or involvement in family planning can be related through bivariate analysis. It was found from the study that the educational status was related to the age of first marriage of the respondents. The Pearson $X^{2}$ test showed that the calculated value was higher than the critical value and asymmetric significance was directing towards a relation between these two. The possible explanation of this correlate was that the awareness and trends towards education of the respondents influenced the age of marriage of the respondents. Similarly, variables like the place of health check up and involvement in family planning were found to be related to educational status of the respondents. The use of contraceptives however, was found not to be related to educational status of the respondents significantly though.

The rest hours in a day of the respondents was found to be related to the complexity during birth giving faced by the respondents. At the same time, age of first marriage was found to be interlinked with the occurrence of major child disease in many cases. The higher the age of first marriage, the lower the occurrence of major child disease was reported. Correlation was tested between living area of the respondents and the supervisor in the time of child delivery. Moderately strong relation was observed between these two while weight standard of the child was found to be related with another association test from the findings. Involvement in heavy work during pregnancy was found to be related to the weight of child during birth. It was observed that the more the involvement in heavy works during pregnancy the less standard weighed child was born to a respondent. 
Table 5. Correlates of Variables Affecting Educational Status Related to Pre-natal and Post-natal Care of the Mothers

\begin{tabular}{|c|c|c|c|c|c|}
\hline $\begin{array}{c}\text { Correlates/Independen } \\
\text { t Variable }\end{array}$ & $\begin{array}{c}\text { Correlates/Dependan } \\
\text { t Variable }\end{array}$ & $\begin{array}{c}\text { Test } \\
\text { Conducte } \\
\text { d } \\
\end{array}$ & $\begin{array}{l}\text { Calculated } \\
\text { Value }\end{array}$ & $\begin{array}{c}\text { Asymmetrical } \\
\text { Significance/St } \\
\text { andard Error }\end{array}$ & $\begin{array}{c}\text { Level of } \\
\text { Confidence }\end{array}$ \\
\hline Educational Status & Age of First Marriage & $\begin{array}{c}\text { Pearson's } \\
X^{2}\end{array}$ & 190.961 & .000 & $5 \%$ \\
\hline Educational Status & $\begin{array}{c}\text { Place of Health Check } \\
\text { up }\end{array}$ & $\begin{array}{c}\text { Pearson's } \\
X^{2} \\
\end{array}$ & 121.281 & .000 & $5 \%$ \\
\hline Rest Hours in a Day & $\begin{array}{c}\text { Complexity during } \\
\text { Birth Giving }\end{array}$ & $\begin{array}{c}\text { Pearson's } \\
X^{2} \\
\end{array}$ & 11.719 & .003 & $5 \%$ \\
\hline Educational Status & Use of Contraceptives & $\begin{array}{c}\text { Pearson's } \\
X^{2} \\
\end{array}$ & 5.111 & .276 & $5 \%$ \\
\hline Educational Status & $\begin{array}{l}\text { Involvement in Family } \\
\text { Planning }\end{array}$ & $\begin{array}{c}\text { Pearson's } \\
X^{2}\end{array}$ & 13.317 & .010 & $5 \%$ \\
\hline Age of First Marriage & $\begin{array}{l}\text { Occurrence of Major } \\
\text { Child Disease }\end{array}$ & $\begin{array}{c}\text { Pearson's } \\
X^{2}\end{array}$ & 13.503 & .003 & $5 \%$ \\
\hline $\begin{array}{c}\text { Living Area of the } \\
\text { Respondents }\end{array}$ & $\begin{array}{c}\text { Supervisor in Child } \\
\text { Delivery }\end{array}$ & Pearson's $r$ & -.589 & .000 & - \\
\hline $\begin{array}{l}\text { Living Area of the } \\
\text { Respondents }\end{array}$ & $\begin{array}{c}\text { Weight Standard of } \\
\text { Child in the Time of } \\
\text { Birth }\end{array}$ & Gamma & .472 & .269 & - \\
\hline $\begin{array}{l}\text { Involvement in Heavy } \\
\text { Work during Pregnancy }\end{array}$ & $\begin{array}{c}\text { Weight of child during } \\
\text { birth }\end{array}$ & $\begin{array}{c}\text { Pearson's } \\
X^{2}\end{array}$ & 4.343 & .114 & $5 \%$ \\
\hline
\end{tabular}

\section{Conclusion}

A healthy Pre-natal and post-natal care is mostly confined to the people of urban areas in Bangladesh. In addition every year huge number of mother $\&$ infants die due to lack of medication. This study found out that there is a significant difference between the rural and urban areas in terms of the aspects involved with pre-natal and post-natal care. Education of the respondents played a greater role in determining the nature of pre0natal and post-natal care as well. Therefore the women education about the pre-natal and post natal becomes very much important. It can help reduce maternal and child mortality which help to achieve million development goals. For a better application of improved health status of the mothers and the children, the education and knowledge regarding the pre-natal and post-natal health care needs to be spread widely in the rural areas as well. The government and non government agencies are trying to do that yet the desired result has not come to the day. Different programs are taken for this and hopes are that the situation will be improved in the future.

\section{References}

[1] Hashima-e-Nasreen, S. M Ahmed, H. A Begum. and K. Afsana, Maternal, Neonatal and Child Health Programmes in Bangladesh. Research Monograph Series No. 32. 2007. Research and Evaluation Division, BRAC.

[2] NIPORT, ORC Macro, John Hopkins University, ICDDR,B., Bangladesh maternal health services and mortality survey 2001. (Dhaka and Claverton: National Institute of Population Research and Training (NIPORT), ORC Macro, John Hopkins University and ICDDR,B, 2003).

[3] MM Parvez, W. Wiroonpanich, M. Naphapunsakul, Bangladesh Journal of Medical Science. Vol 9, No 3, 2010.

[4] MOHFW, Health, Nutrition and Population Sector Programme: Programme Implementation Plan, July 2003-June 2006. (Dhaka: Planning Wing. Ministry of Health and Family Welfare, Government of Bangladesh, 2003).

[5] MK Stewart, B. Parker, J. Chakraborty, and H. Begum, Acute respiratory infections (ARI) in rural Bangladesh: Perceptions and practices. Medical Anthropology; 15. 1994, 377-94.

[6] Vu T., Maternal education and knowledge and practice in childhood acute respiratory infection in Vietnam. Paper presentation, Annual Meeting of the American Sociological Association, 2003.

[7] MR Vitolo, GA. Bortolini, PDB Campagnolo, and CA. Feldens, Effectiveness of a nutrition program in reducing symptoms of respiratory morbidity in children: A randomized field trial. Prevent Med; 47, 2008, 384-388.

[8] MS. Lye, RC Nair, KE Choo, H. Kaur and KP. Lai, Acute respiratory tract infection: A community-based intervention study in Malaysia. J Tropical Pediatric; 42, 1996, 138- 143.

[9] MK Stewart, B. Parker, J. Chakraborty, and H. Begum, Acute respiratory infections (ARI) in rural Bangladesh: Perceptions and practices. Medical Anthropology; 15. 1994, 377-94.

[10] AM. Chowdury, F. Karim, JE. Rohde, J. Ahmed and FH. Abed, Oral rehydration therapy: A community trial comparing the acceptability of homemade sucrose and cereal-based solutions. Bull WHO; 60, 1991, 229-34.

[11] H. Piechulek, A. Al-Sabbir and J. Mendoza- Aldana, Diarrhea and ARI in rural areas of Bangladesh. Southeast Asian J Trop Med Pub Health; 34, 2003, 337-342.

[12] MM Parvez, W. Wiroonpanich, M. Naphapunsakul, Bangladesh Journal of Medical Science. Vol 9, No 3, 2010. 